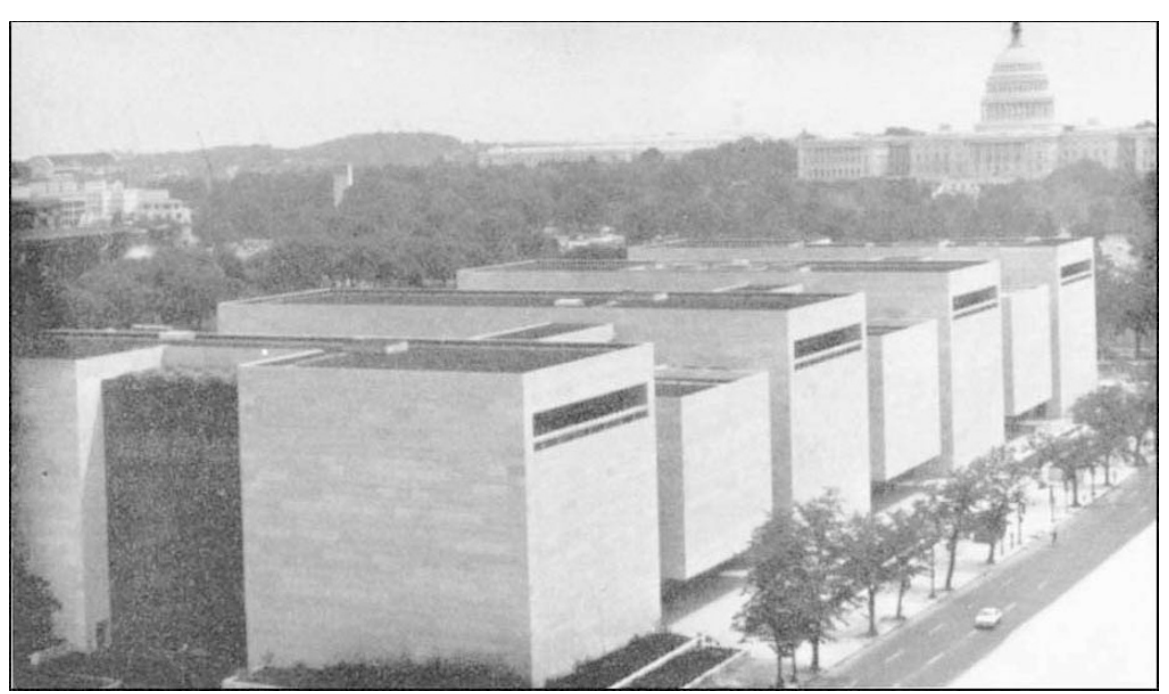

\section{America's history lesson}

\section{Chris Sherwell sees the Smithsonian's latest spectacle in Washington, the National Air and Space Museum}

$\mathrm{T}^{\circ}$ o glide from Washington's white heat of late summer, past the imposing pink marble and tinted window facade of the National Air and Space Museum, and on into the airconditioned splendour of an enormous hall dedicated to the milestones of aviation, is something of an experience. For there, in just one room, is the Wright Brothers' Kitty Hawk; Lindbergh's Spirit of St. Louis; the first plane to break the sound barrier; and the X-15, which has flown at Mach 6.72. And that is just on the 'Air' side. For 'Space', and in the same room, there is a replica of Sputnik and a duplicate of Explorer I; John Glenn's Mercury capsule, Friendship 7; Gemini 4, which carried the first US space walker; a replica of the Mariner 2 interplanetary probe to Venus; the Apollo 11 command module, Columbia; and the first piece of "touchable" lunar rock. It is all a remarkable introduction to a remarkable display.

Nearly three million people have already traversed that hall, and the museum opened only eleven weeks ago; on one particular day, 82,000 people decided to visit. All seek to be informed and educated in an interesting and entertaining way about the history of aerospace. Most leave satiated. The man who piloted 'Columbia' on that memorable moon landing flight, Michael Collins, is the museum's director. He acknowledges that there is no accepted view of what a museum is supposed to do, but at his disposal is a team of 250 , a vast archive, a huge 'spacearium', an enormous theatre with a 55-foot high screen, scores of audiovisual aids and, of course, hundreds of artefacts-which means aircraft and spacecraft. The result is a 23 -section history of flight, beginning with balloons, and ending with the Universe, with digressions into flight and the arts, air-traffic control and the benefits of flight on the way.

Although the balance of the museum's overall display is in favour of Air rather than Space, the most spectacular exhibits are the spacerelated ones. The Skylab Orbital Workshop and Multiple Docking Adaptor, together with the giant Minuteman and other missiles, dominate the second major hall, the Space Hall. Next to these are the Apollo-Soyuz spacecraft and docking module; nearby is a Lunar Module, with the Orbiter and Surveyor satellites suspended above. A room dedicated to the Moon landing project includes a complete rundown on all the crews of manned US spacecraft, a full-size mock-up of the Lunar Module cockpit, displays of experiments performed on the Moon (along with the Lunar Roving Vehicle) and several samples of lunar rock.

None of this could have happened without rockets like the Saturn V, at 353 feet so high that there is room in the museum for only one of its main engines; mirrors have to be deployed to give some idea of the overall size. Rooms on rocketry and rocket history accord due prominence to Goddard, Oberth and Tsiolkovsky, but the television series Star Trek is not forgotten either. The superb satellite room has communications, Earth monitoring, science and weather satellites, but no spy satellites. Collins would like one, but no one acknowledges they exist, $\forall$ and no one has recovered one.

Air sections too have their own attractions and distractions. Apart from the World War rooms, there is, for the more ghoulish, a constantly running film of the last flight of the Hindenburg and film of the more spectacular of the crazy acrobats who flew on planes rather than in them. In the SeaAir Operations rooms visitors can stand on the bridge of an aircraft carrier and watch planes land on the deck, or alternatively (and more alarmingly, since there is no attempt to exI plain the military concept behind an aircraft carrier) join the pilots of the $z$ planes themselves as they go on a short 'mission'. Elsewhere, certain technical principles are exceedingly well demonstrated. There are explanations of the propeller, the turbofan engine, jet propulsion and, in the Flight Technology room, of supersonic flight and even of flight itself.

As always, the problem, even in an aerospace museum, is space-that is, the lack of it. The museum is, in fact, only two-thirds of its originally proposed size. Thus, there has to be some disappointment for everyone. In the third major hall, the Air Transportation Hall, for example, a Douglas DC-3 hangs majestically, "the most important single aircraft type in the history of air transportation". The same could not be done for what may turn out to be the most important planes since-the Lockheed C-5A and the Boeing 707. The problem, of course, is that there is no room for what would need to be another airport in the centre of Washington.

How, then, did Collins and his team decide prionities? "It's an imperfect process", he says; some categoriesFirst and Second World War aviation, for example-chose themselves. One problem, revealed by an early survey of audiences in four of the halls, is that people by-pass important exhibits in their desire to see particular attractions like the Spirit of St. Louis. That exhibit is already the most popular, and Collins suggests that this is something to do with I-indbergh himself: people can relate to his "one-man show" a lot better than they can to the space programme, where there is "a cast of hundreds of thousands".

In fact, although the enormity of the US space effort is more than adequately conveyed by the sheer size of some of the exhibits, the impact which the aerospace industry, indeed flight itself, has had on American people and Western society generally is perhaps insufficiently emphasised. Partly, this is a problem facing any museum, where the idea of history as events, turningpoints and personalities finds its greatest expression. But it is also a matter of perspective. 
Take one particular personality, Howard Hughes - surely the eminence grise of US political and economic life. On the tiny Giants of Air Transportation exhibit the briefest of blurbs says only: "Howard Hughes for many years was the guiding force behind TWA and worked on the design of the Lockheed Constellation". In the larger Flight Technology room, the Hughes H-1 Racer is the centrepiece, and is represented, proudly, as "a major milestone on the road" to Second World War fighters like the the Grumman Hellcat, the Japanese Zero and the German Focke-Wulf FW 190. And in the Benefits of Flight room, Hughes Aircraft and the other major aerospace corporations like Boeing, Lockheed, Rockwell, Northrop, Grumman and McDonnell Douglas, merit just a mere mention on a backdrop list. Nowhere in the museum can the links, if any, between war, politics, the economy and the major corporations be more than guessed at or presumed.

Crucial decisions of the present-in the case of the US, those concerning the so-called "Sale of the Century" of fighter planes, the B-1 Bomber or the Boeing $7 \times 7$ and $7 N 7$-receive little emphasis. There are some elements of topicality - a full-scale model of the Viking Lander, for example. But the biggest gap occurs with the supersonic transport, or SST, of which there is not even a passable model. The decision not to go ahead with this in the USA was, in the view of many, a defeat for science and technology. Not to have an exhibit is a defeat for a museum which aims to look to the future as well as the past, and which actually manages this, if somewhat disappointingly, with the Space Shuttle. Collins himself admits that this may be a weakness, and even allows that, as far as topicality is concerned, the museum "does not do that very well".

Not that the museum fails totally to overcome the problem of presenting history in terms of events. But it does go only a little way towards describing the social impact flight has had. The Benefits of Flight rom is an acknowledgement that the major exhibits do not offer aerospace automatic selfjustification. There the view is expressed-near a deactivated atomic bomb--that flight has contributed to peace rather than war, at least between the major powers ("the sword over Damocles' head"). Exhibits in the same room refer to work on the Earth's resources, to scientific research, to agriculture, to the weather, to communications and so on. A juke-box blaring out Elton John's "Rocket Man" and Frank Sinatra's "Come Fly with Me" spotlights the cultural impact; so does the list of additions to our vocabulary, and the whole Arts room.
But in the areas where the greatest human transformation has been wrought-in population mobility, in the way people think of time and space and, above all, in the way production is organised-the museum shows its greatest weaknesses. How to remedy this? Perhaps the answer lies in the spacearium and theatre, which currently come closest to surmounting the difficulty with the presentations "Cosmic Awakening" and "To Fly", both pitched to a mass audience, and a mass American audience at that.

Above the two floors of display, together with the staff offices, is the library, available by appointment for any researcher to use. It has provided the main documentation for the show below. Collins says he has sought neither to editorialise nor to impose too much uniformity through excessive analysis. He favours an element of surprise instead, treating some subjects more seriously and some more whimsically than others. He agrees that the aim must be to make a presentation that allows an audience to draw its own conclusions, rather than one which makes particular preconceptions and makes certain conclusions inescapable. He acknowledges that some things need to be dressed up just to catch attention, but would hope that the inevitable built-in bias of any museum is in this case acceptable.

Apparently, it is: if the anti-space or anti-business lobbies in the United States believe that he has in fact failed in his task of educating a curious public, their views have gone largely unrecorded. Collins and his staff are plcased with the press they have received. The only serious regret about such a venture must be that it is a National Air and Space Museum, and not an international one.

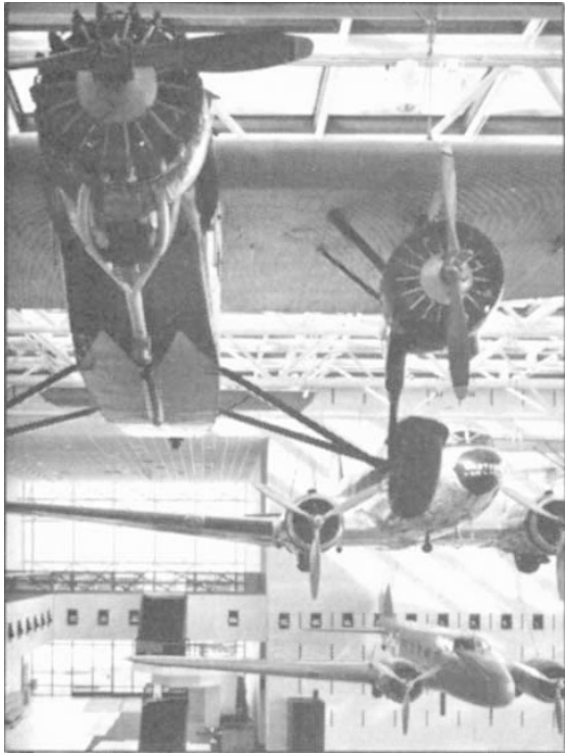

Hall of Air Transportation

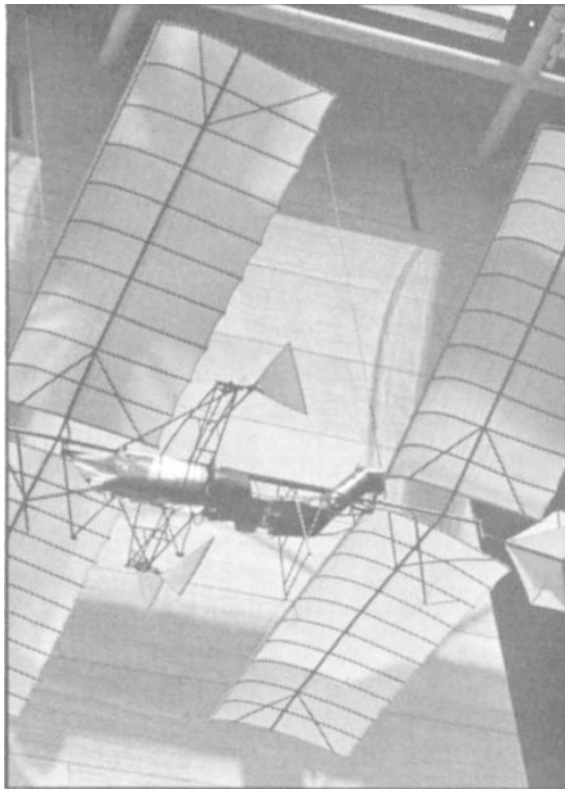

Steam driven aerodrome

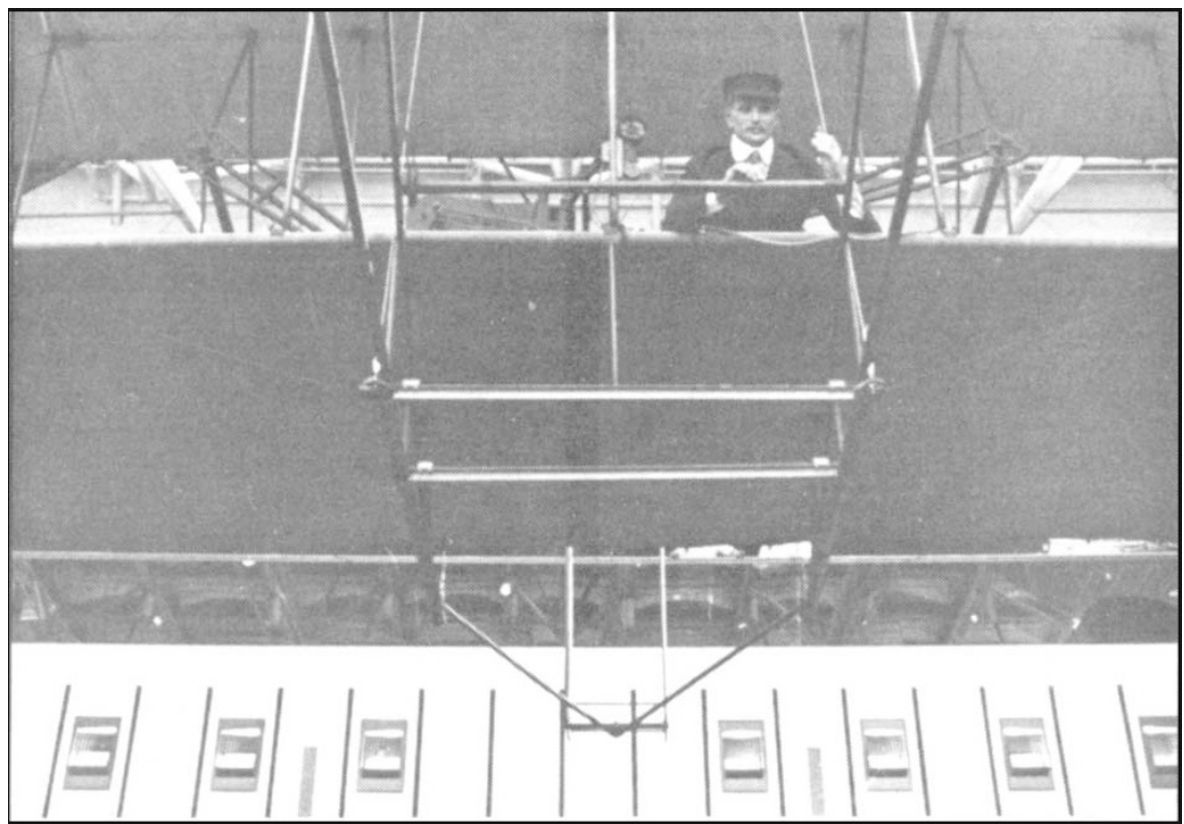

The Wright Brothers' original Kitty Hawk Flyer 